\title{
Taxonomía del género Phalaris L. (Poaceae: Pooideae: Phalaridinae) en Chile
}

\section{Taxonomy of the genus Phalaris L. (Poaceae: Pooideae: Phalaridinae) in Chile}

\author{
VÍCTOR L. FINOT \\ Departamento de Producción Animal, Facultad de Agronomía, Universidad de Concepción, Chillán, Chile. \\ vifinot@udec.cl
}

\begin{abstract}
RESUMEN
Se presenta una revisión taxonómica del género Phalaris L. (Poaceae: Phalaridinae) en Chile. Se reconoce la presencia de 9 especies: P. amethystina Trin., P. caroliniana Walter, $P$. angusta Nees ex Trin., P. aquatica L., P. arundinacea L., $P$. canariensis L., $P$. coerulescens Desf., $P$. minor Retz. y $P$. paradoxa L. Se entregan descripciones, sinónimos, ilustraciones, material estudiado y una clave para las especies. Phalaris coerulescens se cita por primera vez para Chile.
\end{abstract}

Palabras clave: Phalaris, Phalaridinae, Gramineae, Poaceae.

\begin{abstract}
A taxonomic revision of genus Phalaris L. (Poaceae: Phalaridinae) in Chile is given. Nine species are recognized: $P$. amethystina Trin., P. caroliniana Walter, P. angusta Nees ex Trin., P. aquatica L., P. arundinacea L., P. canariensis L., $P$. coerulescens Desf., P. minor Retz. and P. paradoxa L. Descriptions, synonyms, illustrations, specimens examined and a key to species are included. Phalaris coerulescens is cited for the first time in Chile.
\end{abstract}

KeYwords: Phalaris, Phalaridinae, Gramineae, Poaceae.

\section{INTRODUCCIÓN}

Durante la preparación de Poaceae subtribu Phalaridinae para la Flora de Chile, se halló especies de Phalaris L. no citadas para el país. Una de ellas, P. paradoxa L., fue detectada como maleza agrícola en Chile Central y dada a conocer en un trabajo anterior (Finot \& Pedreros 2012). Una segunda especie, $P$. coerulescens Desf., se incluye en este trabajo. Considerando que el tratamiento taxonómico más reciente de las especies chilenas de Phalaris fue realizado por Parodi en 1939 y 1943, el presente trabajo actualiza la taxonomía del género en Chile y entrega descripciones, ilustraciones y una clave para las especies.

Phalaris comprende 21 especies originarias, principalmente, de zonas templadas del hemisferio norte, tanto de la región mediterránea como del sudoeste de los Estados Unidos (Baldini 1995, Tucker 1996, Barkworth 2007, Voshell \& Hilu 2014). En Chile el género Phalaris se encuentra distribuido a lo largo de todo el país, desde Arica a Magallanes $\left(18^{\circ} 30^{\prime}-53^{\circ} 12^{\prime} \mathrm{S}\right)$, representado por 9 especies.
Phalaris es afín a los géneros Anthoxanthum L. y Hierochloe R. Br., que tradicionalmente constituyen la subtribu Phalaridinae Fr., una de las 5 subtribus que componen el "clado ADN cloroplastidial tipo Aveneae" de la Tribu Poeae R. Br. (Soreng et al. 2003). No obstante, la clasificación de estos géneros ha sido controversial y los nuevos antecedentes filogenético-moleculares han abierto nuevamente el debate en torno a su ordenamiento subtribal (Quintanar et al. 2007, Saarela et al. 2010). Tzvelev (1983) clasifica estos géneros en la Tribu Phalarideae Kunth, en la que incluye las subtribus Phalaridinae [Phalaris, Phalaroides Wolf] y Anthoxanthinae A. Gray [Anthoxanthum, Hierochloe]; Clayton \& Renvoize (1986) consideran a Phalaroides un sinónimo de Phalaris e incluye en la Tribu Aveneae Dumort., Subtribu Phalaridinae, a Anthoxanthum, Hierochloe y Phalaris. Nicora (1978) en Flora Patagónica y, posteriormente, Nicora \& Rúgolo (1987) en su tratamiento de los géneros de Gramíneas de América Austral, reconocen la tribu Phalarideae, en la que incluyen los géneros Anthoxanthum, Hierochloe y Phalaris. Tzvelev (1989), no reconoce la Tribu Phalarideae a la que 
trata como sinónimo de la Tribu Phleeae Dumort., en la que reúne 19 géneros, incluyendo Phalaris y Phalaroides, pero no incluye en ella a los géneros Anthoxanthum y Hierochloe sino en la Tribu Poeae. Algunos autores recientes, como Barkworth (2007) incluyen a Phalaris y Anthoxanthum (incl. Hierochloe) en la Tribu Poeae, pero no reconocen en ella subtribus, considerando que tanto la circunscripción de la tribu como la clasificación de los géneros a nivel de subtribu es aún problemática. Quintanar et al. (2007), sobre la base de un estudio filogenético molecular de la tribu Aveneae basada en marcadores cloroplastidiales y nucleares sugieren que Anthoxanthum y Hierochloe debieran clasificarse en la subtribu Anthoxanthineae separados de Phalaris, que quedaría como único género de Phalaridineae. A una conclusión similar llegan Saarela et al. (2010) sobre la base de análisis filogenéticos basados en ADN cloroplastidial y nuclear ribosomal del clado "ADN cloroplastidial tipo Aveneae" de Poeae. Estos autores establecen que la subtribu Phalaridinae no es monofilética, que Anthoxanthum, Hierochloe y Phalaris, aunque constituyen grupos monofiléticos, no son grupos hermanos; que Anthoxanthum/Hierochloe es parte de un clado mayor, que incluye a Agrostidinae y Brizinae; y que la ubicación de Phalaris en el clado ADN cloroplastidial tipo Aveneae de Poeae no es inequívoca; en consecuencia, la circunscripción de la subtribu Phalaridinae para incluir Anthoxanthum/ Hierochloe y Phalaris no parece ser apropiada.

Morfológicamente, estos géneros se caracterizan por tener espiguillas compuestas por un antecio distal (subterminal) fértil acompañado de uno o dos antecios basales estériles (Phalaris, Anthoxanthum) o bien estaminados o estériles (Hierochloe). En Hierochloe, las lemmas basales son tan grandes como el antecio distal fértil; en Anthoxanthum, los antecios basales están usualmente vacíos pero son tan grandes como en Hierochloe; en Phalaris los antecios basales son siempre estériles y muestran la máxima reducción en comparación con Anthoxanthum y Hierochloe.

Phalaris se distingue de Anthoxanthum y Hierochloe por carecer de cumarina (Quintanar et al. 2007); se caracteriza por sus espiguillas 3 -floras, compuestas por un antecio distal fértil y dos antecios estériles basales, usualmente reducidos a pequeñas brácteas representadas por las lemmas, a veces una de ellas o ambas ausentes (reducidas); las glumas cubren totalmente a los antecios y se caracterizan por tener un ala generalmente bien desarrollada en la quilla (ausente o muy angosta en $P$. angusta Nees ex Trin., P. amethystina Trin. y P. caroliniana Walter).

\section{Clasificación infragenérica en Phalaris}

Uno de los pocos autores que discute la división infragenérica de Phalaris es Paunero (1948). Phalaris ha sido dividido en dos secciones: Baldingera (Gaertn.) Koch y Phalaris (como Euphalaris). La sección Baldingera, que incluye únicamente a $P$. arundinacea L., es considerada por algunos autores (v.gr. Tzvelev 1983) como un género monotípico (Phalaroides); esta sección se caracteriza por la panoja laxa y las glumas no aladas, mientras Phalaris posee panoja espiciforme y glumas con la quilla alada. De acuerdo con Paunero (1948) no es posible reconocer las secciones anteriormente señaladas, criterio que también sigue Baldini (1995) en su revisión del género.

\section{Reducción De LoS ANTeCios estériles en PhaLARIS}

En Phalaridinae se puede observar una reducción de los antecios basales estériles que alcanza su máxima expresión en el género Phalaris. Las especies se han agrupado en varias líneas de desarrollo de acuerdo al grado de reducción de los antecios (Anderson 1961, Baldini 1995, Voshell et al. 2011). Las especies que crecen en Chile pueden reunirse en 5 grupos basados en la reducción de los antecios basales:

1. Especies con dos lemmas estériles bien desarrolladas, relativamente anchas, que alcanzan aproximadamente hasta $1 / 2$ del largo de la lemma fértil, como en P. canariensis L., especie introducida en Chile.

2. Especies con dos lemmas estériles reducidas a escamas lineales iguales o subiguales entre sí, menores que $1 / 2$ del largo del antecio fértil, como ocurre en $P$. angusta, $P$. amethystina y P. caroliniana, originarias de América.

3. Especies con dos lemmas muy reducidas que alcanzan como máximo $1 / 3$ del largo de la lemma fértil, tal como ocurre en $P$. arundinacea, especie introducida en Chile.

4. Especies que poseen sólo un antecio con lemma desarrollada, que alcanza no más de 1/3 del largo del antecio fértil; el segundo antecio posee la lemma reducida al callo, como sucede en dos especies, P. aquatica y P. minor, introducidas desde la Europa Mediterránea.

5. Especies que poseen ambas lemmas obsoletas, quedando los antecios reducidos a los callos, como ocurre en $P$. coerulescens y $P$. paradoxa, especies introducidas de la región Mediterránea de Europa.

Historia taxonómica de Phalaris en Chile

Entre los años 1830 y 1864, seis especies de Phalaris fueron descritas para Chile: $P$. amethystina Trin., P. berteroniana Steud., P. chilensis J. Presl, P. colchaguensis Phil., P. robinsoniana Nees ex Steud. y $P$. segetalis Steud. ex Lechler.

La primera especie chilena descrita fue $P$. chilensis $\mathrm{J}$. Presl, sobre la base de material recolectado por Tadeus Haenke en Chile, sin especificar localidad ["hab. in Cordilleris chilensibus, Haenke s.n."]. En la opinión de Desvaux (1854), P. chilensis, excepto por el largo del antecio fértil y de las glumas, este taxón no presenta caracteres que lo distingan de P. angusta, descrito tres años antes (1827) para el sur de Brasil. Por su parte, Parodi $(1939,1943)$ señala que es difícil determinar la identidad de este taxón, que considera cercano tanto a $P$. angusta como a $P$. amethystina Trin. Posteriormente, Soreng et al. (2003) y Zuloaga et al. (2008) lo tratan como un sinónimo de P. angusta, concepto 
que se comparte en este trabajo.

Phalaris amethystina fue descrito en 1839 por Trinius sobre la base de material recolectado en Rancagua por Carlo Bertero; se le considera una buena especie, endémica de Chile, que crece entre las regiones de Coquimbo y de la Araucanía así como en el Archipiélago de Juan Fernández, no obstante es prácticamente imposible de distinguirla de P. caroliniana, originaria de Norteamérica, por caracteres morfológicos. Desvaux (1854), Marticorena \& Quezada (1985) y Zuloaga et al. (2008) aceptan para Chile la presencia de $P$. caroliniana. Aunque la presencia de esta última especie no pudo ser confirmada sobre la base del material estudiado depositado en los herbarios chilenos visitados, no se descarta por ahora su presencia en el país. La especie P. microstachya, que Desvaux (1854) incluye entre los Phalaris presentes en Chile, es un sinónimo de P. caroliniana pero según Parodi (1939, 1943), la especie citada por Desvaux (1854) corresponde a P. amethystina y no a $P$. caroliniana. La confusión se debe probablemente a la estrecha similitud entre ambas especies. Al seguir la clave de Baldini (1995) ellas se separan por la escabrosidad de las glumas (no escabrosas en $P$. caroliniana, escabrosas en P. amethystina) y según Parodi $(1939,1943)$ por el tamaño levemente menor de las glumas de P. caroliniana. Ambos caracteres son, sin embargo, muy variables. Estudios moleculares y biogeográficos recientes separan ambas especies (Voshell et al. 2011, Voshell \& Hilu 2014), por lo que no es posible descartar que $P$. caroliniana esté presente en el país.

En 1854 Nees describió P. robinsoniana Nees ex Steud., publicada sobre la base de un espécimen recolectado por Hugh Cuming en Juan Fernández; esta especie fue transferida al género Phalaridantha por Saint-Léger (1889) [Phalaridantha robinsoniana (Nees ex Steud.) St.Lég.]. Phalaridantha es un nombre ilegítimo, sinónimo de Phalaris y Phalaridantha robinsoniana es un sinónimo de P. amethystina.

En 1854 Steudel describió P. berteroniana Steud., basado en material proveniente de Tagua Tagua, Región de O'Higgins, recolectado por Bertero; esta especie también equivale a $P$. amethystina.

En 1857 Steudel publicó $P$. segetalis Steud. ex Lechler, un nomen nudum actualmente referido a $P$. angusta. Por último, Rodulfo Amando Philippi (1864) describió $P$. colchaguensis Phil. basado en material recolectado por Landbeck en Colchagua, especie que también corresponde a $P$. amethystina.

Phalaris angusta descrito para Brasil, P. amethystina y $P$. caroliniana son las únicas especies americanas. Las restantes especies citadas para el país son plantas europeas: P. arundinacea, P. canariensis, P. caroliniana, P. aquatica y P. minor (Parodi 1939, 1943, Marticorena \& Quezada 1985, Soreng et al. 2003).

Desvaux (1854) en su tratamiento de las Gramineae de
Chile incluyó cuatro especies: $P$. angusta, $P$. canariensis, P. microstachya DC. $(=P$. caroliniana $)$ y $P$. chilensis $(=P$. angusta).

Parodi $(1939,1943)$ menciona cuatro especies: $P$. amethystina, $P$. angusta, $P$. canariensis y $P$. tuberosa var. stenoptera $(=P$. aquatica $)$.

Marticorena \& Quezada (1985) reconocen cinco especies para Chile: P. amethystina, P. angusta, P. aquatica, $P$. caroliniana y P. minor.

Recientemente, Zuloaga et al. (2008) mencionan para Chile seis especies: P. amethystina, P. angusta, P. aquatica, P. canariensis, $P$. caroliniana y P. minor.

Por último, Finot \& Pedreros (2012) citan P. arundinacea cultivado en el sur del país pero también recolectado silvestre entre Chiloé y Magallanes y $P$. paradoxa, recolectado como maleza agrícola en la Región de O’Higgins. En este trabajo se incluye además a $P$. coerulescens, totalizando 9 especies para el país. La presencia de $P$. coerulescens era ya conocida en Chile sobre la base de material cultivado, recolectado por O. Magens en Punta Arenas y depositado en el herbario de la Universidad de Concepción (CONC), pero su presencia en el país no había sido documentada. Recientemente fue recolectada en estado silvestre a la salida oriente de la ciudad de Chillán, a orilla de camino, en un sector actualmente construido.

\section{MATERIALES Y MÉTODOS}

Se estudió el material tipo de las especies chilenas y material de las colecciones generales depositadas en los herbarios CONC y SGO (Holmgren et al. 1990) y en la colección de la Facultad de Agronomía de la Universidad de Concepción. Además se estudió las imágenes digitales de los especímenes tipo disponibles en JSTOR Plant Science (http://plants.jstor.org/). Las observaciones se realizaron con un microscopio estereoscópico Zeiss SV 8 equipado con ocular micrométrico; las mediciones de las estructuras se dan en milímetros (mm). Para distinguir las especies se confeccionó una clave dicotómica. Las especies fueron descritas, ilustradas y se entrega la sinonimia de cada una de ellas, la iconografía, distribución geográfica y el material examinado.

\section{TRATAMIENTO TAXONÓMICO}

Phalaris L., Sp. Pl. 1: 54-55. 1753, nom. cons. Especie tipo: Phalaris canariensis L.

Phalaroides Wolf, Gen. Pl. 11. 1776; Typhoides Moench 1794; Baldingera P. Gaernt. 1799; Digraphis Trin. 1820; Endallex Raf. 1830; Phalaridantha St.-Lag. 1889.

Hierbas anuales o perennes rizomatosas o cespitosas, erectas o ascendentes con tallos geniculados en la base, 
10 a $200 \mathrm{~cm}$ de alto. Hojas lineares a lanceoladas, anchas o angostas, planas, glabras; lígula hialina. Inflorescencia una panícula generalmente espiciforme, a veces contraída (P. arundinacea). Espiguillas homógamas hermafroditas o bien heterógamas dispuestas en grupos compuestos de 1-2 espiguillas fértiles hermafroditas sésiles o pediceladas y 5-6 espiguillas estériles pediceladas. Espiguillas fértiles comprimidas lateralmente, compuestas de 2-3 antecios, el terminal fértil acompañado de 1-2 antecios basales estériles; desarticulación de la raquilla sobre las glumas; glumas 2, membranosas, aquilladas, a veces aladas en la quilla, usualmente 3-nervias, glabras o escabrosas, agudas o acuminadas; antecio fértil ovado, lateralmente comprimido, con la lemma más firme que las glumas, generalmente cubierta de pelos adpresos; pálea glabra o pubescente; lodículas 2, membranosas. Anteras 3, con dehiscencia longitudinal. Antecios estériles (0-)1-2, vacíos, reducidos a la lemma linear, subulada o lanceolada, membranosa, glabra o pilosa. Espiguillas estériles masculinas o neutras.

Género con 22 especies en el mundo, 9 de las cuales se encuentran en Chile, frecuentemente en sitios uliginosos y campos cultivados. Pueden presentarse como malezas (P. aquatica, $P$. paradoxa) o se cultivan para forraje ( $P$. aquatica, $P$. arundinacea, $P$. canariensis). Aunque en general las especies de Phalaris se consideran valiosas forrajeras, algunas como $P$. coerulescens, $P$. paradoxa y $P$. angusta son responsables de intoxicaciones en animales de ganado (caballos, bovinos) (Colegate et al. 1999, Sousa \& Irigoyen 1999, Offord 2006). Phalaris canariensis, así como de otras especies, han sido investigadas en relación con la silicificación de los macropelos y células epidérmicas de las lemmas. Se ha sugerido que los macropelos pueden ser importantes en la etiología de cáncer esofágico en Irán, donde se ha encontrado que contaminan la harina de trigo (Hodson et al. 1984, Perry et al. 1984).

Una especie, $P$. amethystina, es endémica de Chile. Phalaris angusta, nativa de América, se encuentra tanto en Norteamérica como en Sudamérica y ha sido introducida en Europa y Sudáfrica. Las restantes especies presentes en Chile son introducidas.

\section{Clave para las especies de Phalaris en Chile}

1. Espiguillas heterógamas, reunidas en grupos de 7, la espiguilla central fértil rodeada de seis espiguillas estériles; glumas con ápice acuminado o aristado, aladas

2. Plantas anuales; quilla de las glumas con un diente triangular en la zona media o tercio superior

2'. Plantas perennes; quilla de las glumas eroso-denticuladas . 9. P. paradoxa

1'. Espiguillas homógamas, todas fértiles

3. Hierbas perennes, panícula laxa o espiciforme

4. Panícula contraída, angosta, de 5-20 cm de largo, lobada, densa o interrupta abajo, expandiéndose a la antesis, las ramas inferiores de hasta $5 \mathrm{~cm}$ de largo; rizomas presentes; glumas no aladas .................................. 4. P. arundinacea

4'. Panícula espiciforme de 5-15 cm de largo, no expandiéndose a la antesis; entrenudos basales subbulbosos; glumas aladas

ierbas anuales, panícula siempre espiciforme

5. Glumas no aladas o con ala muy angosta

6. Glumas escabrosas, con nervio medio prominente fuertemente escabroso; panícula angosta, linear, de hasta $20 \mathrm{~cm}$ de largo; espiguillas 2-3-floras de 2,5-5,0 mm; lemma fértil de 2,8-3,2 mm; lemmas estériles de 0,5-1,5 mm, pilosas .....

6'. Glumas no escabrosas, sin nervio medio escabroso prominente; panícula subovoide de 1,0-7,5 cm de largo; espiguillas 3-floras de 5,0-6,5 mm; lemma fértil de 2,9-3,4 mm; lemmas estériles de 1,1-2,0 mm, glabras

1. P. amethystina, 6. P. caroliniana

5'. Glumas anchamente aladas

7. Espiguillas 2-floras de 5,0-5,6 mm de largo; lemma fértil de 3,0-3,5 mm; lemma estéril de 1,0-1,1 mm, alcanzando 1/3 del largo de la lemma fértil, pilosa; anteras de $1-2 \mathrm{~mm}$ de largo ........................................ 8. P. minor

7'. Espiguillas 3-floras de 5,0-8,0 mm de largo; lemma fértil de 4,7-5,5 mm; lemmas esteriles de 2,5-3,5 x 0,5 mm, alcanzando cerca de $1 / 2$ del largo de la lemma fértil, subglabra o esparcidamente pilosa; anteras de 3-4 mm de largo .....

1. Phalaris amethystina Trin., Mém. Acad. Imp. Sci. SaintPétersbourg, Sér. 6, Sci. Math., Seconde Pt. Sci. Nat. 5,3(3): 56. 1839. Tipo: Chile, in pascuis herbidis aquosis montis La Leona Rancagua, Bertero 534 (lectotipo: LE; isolectotipo: SGO!). Figura 1 D-E.

Phalaris berteroniana Steud., Syn. Pl. Glumac. 1: 11. 1855[1853]. Tipo. Chile, in saxosis sterilibus secus torrentes Tagua Tagua, 1825, Bertero 553 (holotipo: $\mathrm{P}$ imagen internet!). OBS: El holotipo $\mathrm{P}$ lleva el número
Bertero $h r b r . N^{\circ} 533$ en el protólogo se menciona Bertero 553.

Phalaris robinsoniana Nees ex Steud., Syn. Pl. Glumac. 1: 11. 1854. Phalaridantha robinsoniana (Nees ex Steud.) St. Lag., Étude Fl. ed. 8, 2: 900. 1889. Tipo. Chile, Juan Fernandez isl., Cuming 1346 (lectotipo: K; isolectotipos: $\mathrm{BM}$ imagen internet!, K imagen internet!, TCD imagen internet!). 
Phalaris colchaguensis Phil., Linnaea 33(3-4): 276. 1864.

Tipo. Chile, Colchagua, Landbeck s.n. 1860 (holotipo:

SGO!; isotipos: LP-24195 imagen internet!).

Iconografía. L.R. Parodi, Rev. Argent. Agron. 6: 81, fig. 1B-C; R. Baldini, Webbia 49(2): 304, fig. 10. 1995.

Hierbas anuales; cañas de $15-80 \mathrm{~cm}$ de alto, erectas o geniculadas en la base; entrenudos de 3,5-15 cm de largo, estriados, glabros; nudos 3-5, glabros. Vainas de 2-5,5 cm de largo, usualmente más cortas que los entrenudos, estriadas, glabras; lígulas hialinas de 2,5-6 mm de largo, truncadas en el ápice, glabras en el dorso; láminas linear-lanceoladas, de 3-14 $\mathrm{cm}$ de largo, 1,5-6,5 $\mathrm{mm}$ de ancho, planas, con el ápice agudo, glabras, finamente escabrosas en los márgenes. Panículas espiciformes, oblongas, densas, de 1,5-7,5 $\mathrm{cm}$ de largo, 0,8-1,5 cm de ancho, verdes. Espiguillas 3-floras, de 5-6,5 $\mathrm{mm}$ de largo, brevemente pediceladas; pedicelos de $0,7-1,1 \mathrm{~mm}$ de largo, escabrosos; glumas iguales o subiguales, no aladas o muy angostamente aladas, de 4,55,2 $\mathrm{mm}$ de largo, 0,8-1 $\mathrm{mm}$ de ancho, agudas, 3-nervias, con nervios laterales prominentes, escabrosos, quilla finamente denticulada, de color blanquecino, con una franja longitudinal más oscura, de color verde, frecuentemente purpúreas hacia el ápice. Antecio fértil de 2,9-3,4 $\mathrm{mm}$ de largo; lemma pilosa, aguda; pelos adpresos distribuidos principalmente hacia la mitad superior; pálea de 2,5-2,8 mm de largo, con pelos sólo en la mitad superior de la quilla; lodículas hialinas, agudas, de 1,2 $\mathrm{mm}$ de largo, glabras. Antecios estériles 2; lemmas estériles de 1,1-2 mm de largo, subiguales, membranosas, glabras, brillantes, agudas, con pelos en el callo y en el ápice.

Distribución geográfica. Especie endémica de Chile, con distribución restringida a la zona centro-sur del país, entre las regiones de Coquimbo y de Los Lagos y en el Archipiélago de Juan Fernández (Masatierra) (Parodi 1939, Baeza et al. 2002, 2007). Crece principalmente a bajas altitudes, pero alcanza los $1.000 \mathrm{~m}$ s.m. En la depresión intermedia crece en el espinal de Acacia caven (Molina) Molina, en suelos planos, ricos, franco arcillosos, con aguas superficiales. Florece entre septiembre y enero.

Material estudiado. CHile. Región de Coquimbo, Prov. Coquimbo, Ovalle, Quebrada Toigoncillo, 250 m, 19-IX1948, Jiles 852 (CONC); Carretera Panamericana, entre Pichidangui y Los Vilos, 12-X-1963, Marticorena \& Matthei 37 (CONC); Illapel, cumbre de la cuesta Los Cristales, entre Illapel y Salamanca, 20-24-X-1941, Muñoz \& Johnson 2402 (SGO); Illapel, cuesta de Guenchiguallego, a $50 \mathrm{~km}$ al oeste de Illapel, 100 m, 20-24-XI-1941, Muñoz \& Johnson 2275 (SGO). Región de Valparaíso, Prov. Marga-Marga, Limache, Pangal, 16-X-1932, Garaventa 2836, 2837 (CONC, SGO); Limache, Lliu-Lliu, 14-XI-1931, Garaventa 2257 (SGO); Archipiélago de Juan Fernández, Germain s.n. año 1854 (SGO); Masatierra, Horst s.n. año 1911 (SGO). Región de
O’Higgins, Cerro La Leona, Rinconada de Chancón, 7-XII1941, Muñoz \& Johnson 2655 (SGO); Palmería de Cocolán, bajo el bosque de Jubaea, 24-X-1942, Muñoz et al. 3521 (SGO). Región Metropolitana, Prov. Santiago, R.N. Río Clarillo, 800 m, 4-X-1985, Araya s.n. (CONC); Santiago, Hacienda Rinconada de Cerda, Maipú, Quebrada de La Plata, 750 m, 2-X-1941, Muñoz \& Johnson 2131 (SGO); Maipo, Paine, Chada, 25-X-1936, Muñoz s.n. (SGO); Maipo, Laguna de Aculeo, 356 m, 11-X-1942, Pisano et al. 1543 (SGO). Región del Maule, Prov. Cauquenes, camino Parral-Cauquenes, 5-XI-1993, Finot et al. 479 (CONC$\mathrm{CH}$ ); Cauquenes, Subestación experimental Cauquenes INIA El Boldo, X-1980, Avendaño s.n. (SGO); Cauquenes, 177 m, 23-X-1942, Silva 249 (SGO); Cauquenes, Estación genética, 23-XII-1940, Letelier 23 (SGO). Región del Bío-Bío, Prov. Nuble, camino Chillán-Bulnes km 419.5 por carretera panamericana, en espinal de Acacia caven, 20-XI-2006, Finot \& Solís 2247 (CONC-CH); Sur de Chillán, Sur de Nebuco en ruta 55, ca $2 \mathrm{~km}$ al sur de la salida a Concepción, 125 m, 12-XI-2001, Soreng \& Soreng 7012 (CONC); Mulchén, XI-1941, Sepúlveda s.n. (SGO); Ninhue, Hacienda San Agustín de Puñual, 11-XI-1995, Finot 174 (CONC-CH). Región de la Araucanía, Malleco, Angol, Los Alpes, El Vergel, 16-XI-1933, Reed s.n. (SGO); Angol, Los Alpes, El Vergel, 7-8-XI-1941, 300 m, Muñoz 2468 (SGO). Región de Los Lagos, Osorno, Fundo Cañal Bajo, 13-XI-1953, Gutiérrez s.n. (SGO).

2. Phalaris angusta Nees ex Trin., Sp. Gram. 1: t. 78. 1827. Phalaris intermedia Bosc ex Poir. var. angusta (Nees ex Trin.) Chapm., Fl. South. U.S. 569. 1860. Tipo: Brasilia meridionali. Pl. 78 en Trinius (1928) (lectotipo: $\mathrm{K}$ imagen internet!). Figura $1 \mathrm{~F}-\mathrm{G}$.

Phalaris chilensis J. Presl, Reliq. Haenk. 1(4-5): 245. 1830. Tipo: Hab. in Cordilleris chilensibus, Haenke s.n. (lectotipo: PCR no visto).

Phalaris intermedia Bosc ex Poir. var. angustata Beal, Grasses N. Amer. 2: 182. 1896. Tipo: Cultivated from California, Pringle 15086 (lectotipo: MO-1837515 imagen internet!; isolectotipos: F-210177 imagen internet!, PH-1087785 imagen internet!).

Phalaris laxa Spreng. ex Steud., Nomencl. Bot. (ed. 2) 2: 315. 1841. Nombre inválido citado como sinónimo de P. angusta Nees.

Phalaris ludoviciana Torr. ex Trin., Mém. Acad. Imp. Sci. St-Pétersb. Sér 6. Sci. Math. Seconde Pt. Sci. Nat. 5,3(3): 56. 1839. Nombre inválido citado como sinónimo de $P$. angusta Nees.

Phalaris segetalis Steud. ex Lechler, Berberid. Amer. Austr. 52. 1857. Nomen nudum.

ICONOGRAFÍA. Hitchcock, A.S., Man. Grasses U.S.: 554, fig. 802. 1951. 


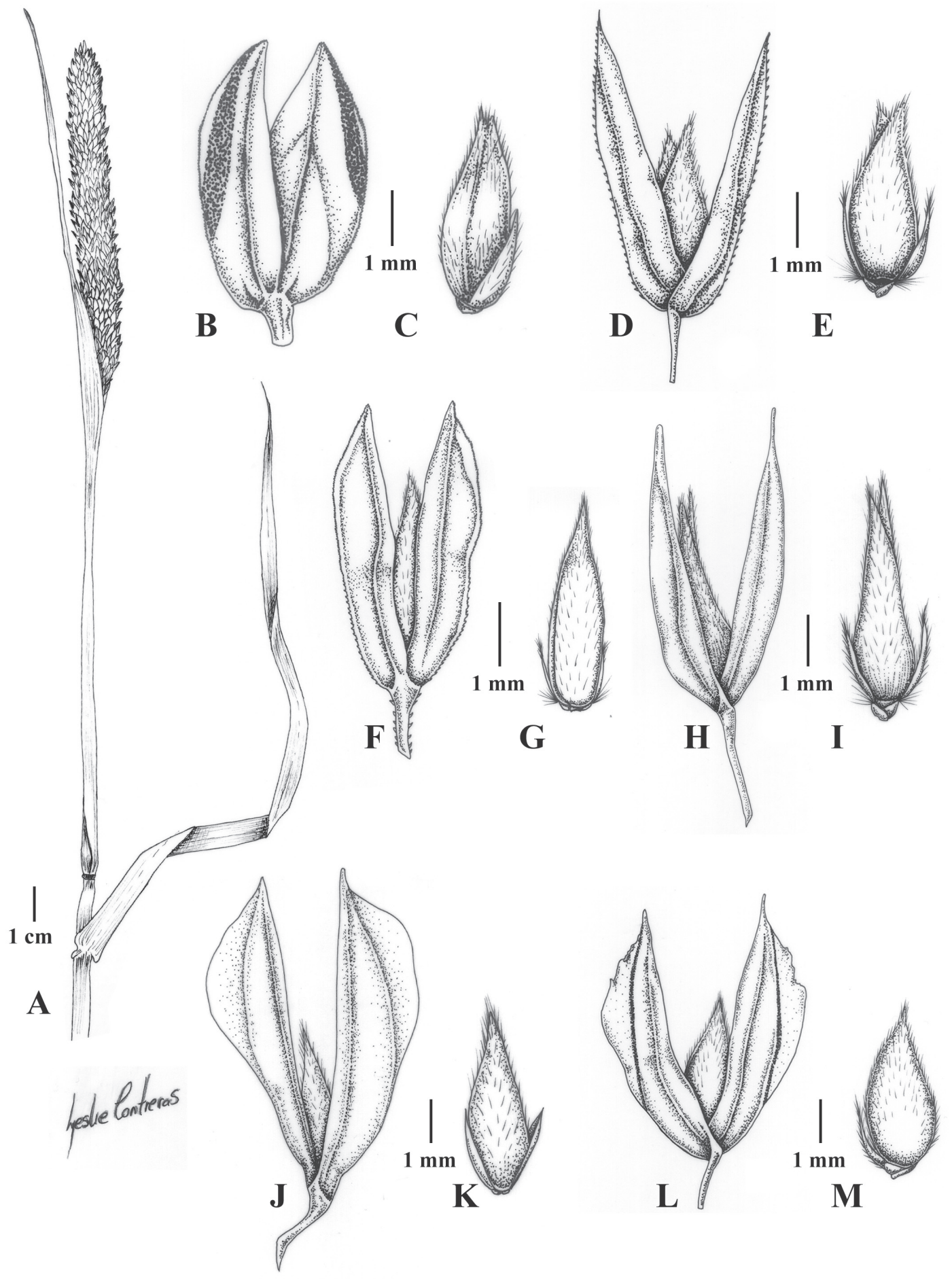

Figura 1. A-C. Phalaris aquatica L. (Finot et al. s.n.). A. Inflorescencia. B. Espiguilla. C. Antecios. D-E. P. amethystina Trin. /caroliniana Walter (Finot et al. 479). D. Espiguilla. E. Antecios. F-G. P. angusta Nees ex Trin. (Montero 2089). F. Espiguilla. G. Antecios. H-I. P. arundinacea L. (Parilo s.n.). H. Espiguilla. I. Antecios. J-K. P. canariensis L. (Gunckel 25214). J. Espiguilla. K. Antecios. L-M. P. minor Retz. (Jiles 3038). L. Espiguilla. M. Antecios.

Figure 1. A-C. Phalaris aquatica. A. Inflorescence. B. Spikelet. C. Florets. D-E. P. amethystine /caroliniana Walter (Finot et al. 479). D. Spikelet. E. Florets. F-G. P. angusta Nees ex Trin. (Montero 2089). F. Spikelet. G. Florets. H-I. P. arundinacea L. (Parilo s.n.). H. Spikelet. I. Florets. J-K. P. canariensis L. (Gunckel 25214). J. Spikelet. K. Florets. L-M. P. minor Retz. (Jiles 3038). L. Spikelet. M. Florets. 
Hierbas anuales, de (10-)50-60(-170) cm de alto, geniculadas en la base; entrenudos de $6-18,5 \mathrm{~cm}$ de largo, estriados, glabros; nudos 4-5, glabros. Vainas abiertas de 6,5-12 cm, estriadas, glabras, poco más cortas que los entrenudos; lígulas de 4-7 mm de largo, hialinas, truncadas, a menudo laciniadas; láminas planas, de $8-15 \mathrm{~cm}$ de largo por 4-7 $\mathrm{mm}$ de ancho, planas, escabrosas en ambas caras y en los márgenes, agudas en el ápice. Panículas de 4-13 $\mathrm{cm}$ de largo por 8-10 $\mathrm{mm}$ de ancho, espiciformes, densas, cilíndricas, angostas, a veces lobadas. Espiguillas de 2,5-5 $\mathrm{mm}$ de largo, subsésiles o con pedicelo de hasta $1 \mathrm{~mm}$ de largo, algo escabroso; glumas de 2,5-5 $\mathrm{mm}$ de largo por 0,6$1 \mathrm{~mm}$ de ancho, subiguales, angostas, 4-5 veces más largas que anchas, con nervios laterales prominentes y fuertemente escabrosos, la quilla no alada o con un ala muy angosta restringida a los $2 / 3$ superiores, finamente denticulada; antecios 2-3. Antecio fértil: lemma de 2,8-3,2 mm de largo, pilosa, aguda; pálea de $2,5 \mathrm{~mm}$ de largo, pilosa hacia el ápice; anteras de 0,5-1 mm de largo. Antecios estériles 1 ó 2: lemmas de 0,5-1,5 mm de largo, subiguales, pilosas, papiráceas.

Distribución GEOGRÁfICA. Especie americana, en Norteamérica crece en los Estados Unidos y México y en Sudamérica en Argentina, Bolivia, Brasil, Chile, Ecuador, Paraguay, Perú y Uruguay. También ha sido introducida en Europa y en Sudáfrica (Rúgolo et al. 2008). En Chile crece desde la Región de Valparaíso (30¹9'S) a la de Los Lagos ( $\left.42^{\circ} 28^{\prime} \mathrm{S}\right)$, entre los 10 y los $175 \mathrm{~m} \mathrm{s.m}$. Especie de interés como planta forrajera (Rúgolo et al. 2008).

Material estudiado. CHILE, Región del Bío-Bío, Mininco, 13-XI-1952, Kunkel 565 (SGO). Región de la Araucanía, Prov. Cautín, Carahue, Trovalhue, 12 m, 3-I-1935, G. Montero 2089 (CONC). Región de Los Ríos, Valdivia, 100 m, 25-XI-1932, Hollermayer 1249 (SGO); Valdivia, Quinchilca, 70 m, XII-1939, Hollermayer 1237 (SGO). Región de Los Lagos, Chiloé, Castro, 60 m, 27-28-II-1942, Pisano \& Zavlezo 1312 (SGO); Castro, El Tranque, $60 \mathrm{~m}$, 3-III-1942, Pisano \& Zavlezo 1301 (SGO).

3. Phalaris aquatica L. Cent. I. Plant. 4. 1755. Figura 1A-C.

Phalaris altissima Menezes, Cat. Phanerogam. Madeira Porto Santo 58. 1894.

Phalaris stenoptera Hack., Repert. Spec. Nov. Regni Veg. 5: 333. 1908. TIPO: Cult.: Patria ignota, culta in Australia sub nomine Phalarides commutatae. Plantam et semina misit A. J. Ewart, Melbourne. Phalaris tuberosa var. stenoptera (Hack.) Hitchc., J. Wash. Acad. Sci. 24(7): 292. 1934. Phalaris aquatica var. stenoptera (Hack.) Burkart, Fl. Il. Entre Ríos (Argentina) 2: 115. 1969.

Phalaris arundinacea subsp. bulbosa Paunero, Anal. Jard. Bot. Madrid 8: 489. 1947.
Phalaris tuberosa var. alata Trab., Fl. Algérie 141. 1895. Phalaris bulbosa var. alata (Trab.) Maire \& Weiller, Flore de l'Afrique du Nord: 2: 18. 1953.

Phalaris tuberosa var. clausonis Maire \& Trab., Bull. Soc. Hist. Nat. Afrique N. 24(7): 230. 1933. Phalaris bulbosa var. clausonis (Maire \& Trab.) Maire \& Weiller, Fl. Afrique N.: 2: 18. 1952.

Phalaris bulbosa var. genuina Maire, Fl. Afrique N.: 2: 18. 1953; nom. inval.

Phalaris bulbosa var. hirtiglumis Trab., Bull. Soc. Bot. Fr. 32(7): 395. 1885; nom. nud.

Phalaris commutata Roem. \& Schult., Syst. Veg. 2: 403. 1817. TIPO: Bertoloni s.n. Genuae in canali supra il Lagazzo, lectotipo.

Phalaris elongata Braun-Blanq., Bull. Soc. Hist. Nat. Afrique N. 13: 21. 1922. TIPO: Marruecos, Chichaoua, buissins a Ziziphus lotus, 5 Abr 1921, Braun-Blanquet s.n..

Phalaris nodosa Murray, Syst. Veg. Ed. 13: 88. 1774; nom. ilegit.

Phalaris nodosa var. minor Lojac., Fl. Sicul. (Lojacona) 3: 251. 1908.

Phalaris tuberosa L., Mant. Pl. 557. 1771. TIPO: Habitat in Europa australi.

ICONOGRAFÍA. Tovar, O. Ruizia 13: 166, fig. 18 j-k. 1993.

Hierbas perennes, rizomatosas, con tallos engrosados en la base, de hasta 1,5-2 m de alto; entrenudos de 11-24 cm de largo, estriados, glabros; nudos 5-7, glabros. Vainas de 9,5-11,5 cm de largo, abiertas en el ápice, estriadas, glabras, más cortas que los entrenudos; lígulas hialinas, de 4-5 mm de largo, glabras; láminas de $10-25 \mathrm{~cm}$ de largo por 5,5$8 \mathrm{~mm}$ de ancho, escabrosas. Panículas de 3,5-15 x 1,2-3 $\mathrm{cm}$, densas, espiciformes, cilíndricas, a menudo lobadas en la base, verdes, a veces débilmente teñidas de púrpura. Espiguillas de 5-5,5 $\mathrm{mm}$ de largo, 2-3-floras, pediceladas, los pedicelos glabros de 0,5-1,5 mm de largo; glumas subiguales, de 4,8-5,5 x 1,2-1,5 mm, glabras, ampliamente aladas, 3-nervias, los nervios laterales no escabrosos; ala entera, teñida de verde; glumas inferiores algo más angostas que las superiores; lemma fértil de 3-4 $\mathrm{mm}$ de largo, pilosa hacia el ápice; pálea de 2,7-3,5 mm de largo, pilosa en la quilla; lodículas de $0,5 \mathrm{~mm}$ de largo, hialinas; anteras de 3-3,5 mm de largo; antecios estériles 1 ó 2; lemma estéril de 1-1,5 mm de largo, pilosos.

Nombres comunes. Mata dulce; triguera caballuna.

Número de CROMOSOMAs. $2 \mathrm{n}=28$ (Hanson $\&$ Hill, 1953 bajo Ph. tuberosa).

Distribución geográfica. De acuerdo con Baldini (1995) es propia de los Archipiélagos Macaronésicos y de la Región Mediterránea y ha sido introducida en África, América y Oceanía (Australia). En Chile crece desde Arica y Parinacota 
$\left(18^{\circ} 29^{\prime} \mathrm{S}\right)$ a Magallanes $\left(53^{\circ} 10^{\prime} \mathrm{S}\right)$, en áreas disturbadas, orillas de caminos y canales con inundaciones estacionales, desde el nivel del mar hasta los $740 \mathrm{~m}$ de altitud. Especie de interés forrajero (Barkworth 2007).

Material estudiado. CHiLE. Región de Arica y Parinacota, Arica, Valle de Azapa, 50 m, X-1979, Escobar s.n. (CONC). Región de Coquimbo, Prov. Cardenal Caro, camino de Marchihue a Alcones, entre puentes Las Cadenas 1 y 2, 140 m, 29-IX-1989, Matthei \& Quezada 747 (CONC). Región de O'Higgins, Prov. Cardenal Caro, Pichilemu, 15 m, 7-XII1973, Montero 9279 (CONC). Región Metropolitana, Prov. Santiago, Quebrada la Plata, Quebrada Los Maquis, 740 m, 5-XII-1967, Schlegel 6131 (CONC). Región del Maule, Prov. Linares, camino Parral-Cauquenes a $1 \mathrm{~km}$ de Parral, 5-XI-1993, Finot et al. s.n. (CONC-CH); Prov. Talca, Chanco, R.N. Federico Albert, 8-I-2001, Matthei \& Finot 48 (CONC). Región del Bío-Bío, Hualpén, Playa Blanca, 26-XII-1941, Pfister 375 (SGO); Prov. Ñuble, Chillán, 19IX-2006, Cortez et al. s.n. (CONC-CH); Chillán, XI-1964, Altmann s.n. (CONC); Chillán, Campus Universidad de Concepción, 12-I-1992, Rodríguez \& Solís s.n. (CONC$\mathrm{CH})$; camino entre San Nicolás y Ninhue, sector Los Montes, 15-XI-2005, Arriagada 33 (CONC-CH); Ninhue, Hacienda San Agustín de Puñual, cerro Coiquén, 25-XI1995, Finot 273 (CONC-CH); camino Chillán-Bulnes, Larqui, 20-XI-2004, Finot 2051 (CONC-CH). Región de la Araucanía, Malleco, Curacautín, Termas de Río Blanco, El Toro, XII-1951, Acevedo s.n. (SGO). Región de Los Lagos, Osorno, Fundo Cañal Bajo, Genética de Osorno, sin fecha, García 19 (SGO); Osorno, Fundo Cañal Bajo, 13-XII-1953, Gutiérrez s.n. (SGO). Región de Magallanes, Punta Arenas, en jardín, III-1957, Magens 3543 (CONC).

Comentarios. No existe uniformidad entre los autores en cuanto al número de antecios estériles presentes en la espiguilla de P. aquatica. Según Baldini (1995) puede poseer 1 ó 2 antecios estériles, pero señala que sí hay dos antecios estériles uno de ellos está muy reducido alcanzando cerca de $0,5 \mathrm{~mm}$ de largo. Rúgolo et al. (2005) señalan para $P$. aquatica var. stenoptera la presencia de un antecio estéril reducido a un callo basal y un segundo antecio estéril más desarrollado de ca. 1,5 mm de largo. Por su parte, Renvoize (1998) señala para esta especie 2 antecios estériles en la clave y sólo un antecio estéril en la descripción de la especie. En todos los especimenes chilenos examinados se observó la presencia de un único antecio estéril.

4. Phalaris arundinacea L., Sp. Pl. 1: 55. 1753. Typhoides arundinacea (L.) Moench, Methodus 202. 1794. Baldingera arundinacea (L.) Dumort., Observ. Gramin. Belg. 130, t. 10, f. 40. 1824. Phalaridantha arundinacea (L.) St. Lager \& St.-Lag., Étude Fl. (ed. 8), 2: 900. 1889. Phalaroides arundinacea (L.) Rauschert,
Feddes Repert. 79(6): 409. 1969. Tipo: Habitat in Europae subhumidis ad ripas lacuum. Figura 1 H-I.

Hierbas perennes, rizomatosas, de 50-200 $\mathrm{cm}$ de alto. Vainas de hasta $17 \mathrm{~cm}$ de largo, estriadas, glabras; lígula de 7-8 $\mathrm{mm}$, hialina; láminas de $20-30 \mathrm{~cm}$ de largo por $11-15 \mathrm{~mm}$ de ancho. Panículas de 9-20 $\mathrm{cm}$ de largo por 2,5-5 $\mathrm{cm}$ de ancho, abiertas a la madurez, lobadas, con ramas inferiores de 2,5-5 $\mathrm{cm}$ de largo; raquis esparcidamente escabroso. Espiguillas de 4-6,5 mm, 3-floras, pediceladas, los pedicelos de 1-3 $\mathrm{mm}$ de largo, escabrosos; glumas subiguales, no aladas, de 4,3-6,5 x 0,8-1 mm, glabras, agudas, 3-nervias, los nervios laterales lisos, prominentes; antecio fértil de 3,5-4 mm, esparcidamente piloso hacia el ápice; pálea de 3,5-4 mm, pilosa sobre la quilla; anteras de 2,8-3,8 $\mathrm{mm}$; lodículas de 1-1,2 mm, agudas, pilosas, a veces ausentes; antecios estériles 2, de 1-1,5 mm, membranosos, pilosos.

Número de CROMOSOMAS. $2 \mathrm{n}=14,28$ (Nielsen \& Humphrey 1937); plantas aneuploides con 27, 29, 31 y 35 cromosomas fueron informadas por Hanson \& Hill (1953).

Distribución GeOGRÁficA. Especie propia del hemisferio norte, ha sido introducida en Norteamérica, Sudamérica y Australia por su valor forrajero y ornamental (Baldini 1995). En Chile se encuentra desde la Región de la Araucanía

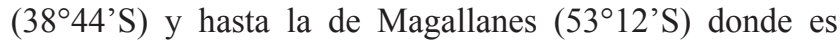
frecuentemente cultivada. Crece desde el nivel de mar hasta aproximadamente $300 \mathrm{~m} \mathrm{s.m.}$

Material estudiado. CHile. Región de la Araucanía, Prov. Cautín, Temuco, XII-1968, Montero 9198 (CONC). Región de Los Lagos, Prov. Osorno, Isla Fresia, Lago Puyehue, II-1957, Levi 3352 (CONC). Región de Magallanes y Antártica Chilena, Prov. Magallanes, Punta Arenas, XII2006, Parilo s.n. (CONC-CH); Punta Arenas, jardín, IIIIV-1955, Magens 3186 (CONC).

5. Phalaris canariensis L., Sp. Pl. 1: 54. 1753. Tipo: Habitat in Europa australi, Canariis (lectotipo LINNHS116 imagen internet!). Figura $1 \mathrm{~J}-\mathrm{K}$.

Phalaris ovata Moench, Methodus 208. 1794. Tipo: Plantas hortenses.

Phalaris avicularis Salisb., Prodr. Stirp. Chap. Allerton 17. 1796.

Phalaris canariensis subsp. typica Posp., Fl. Oesterr. Kustenl. 1: 59. 1897. Nom. inval. (Art. 24).

Phalaris canariensis var. debilis Tocj \& Rohlena, Sitzungsber. Konigl. Bohm. Ges. Wiss. Prag, Math.Maturwiss. Cl. 49: 1. 1902.

Phalaris canariensis var. subcylindrica Thell., Vierteljahrsschr. Naturf. Ges. Zurich 56: 271. 1912.

Phalaris canariensis f. vivipara Junge, Jahrb. Hamburg. Wiss. Anst. 30: 123. 1912. 
Phalaris canariensis f. bracteata Jansen \& Wacht., Ned. Kruidk. Arch. 6: 135. 1917. Tipo: Netherlands, Zaanoever, Jul. 1915, Jansen \& Wachter 11728. Holotipo: L.

Phalaris canariensis fo. colorata Jansen \& Wacht., Ned. Kruidk. Arch. 52: 213. 1942. Tipo: Jansen, Kruscmar \& Koopman 43048. Lectotipo: L.

Phalaris canariensis var tenuis Jansen \& Wacht., Ned. Kruidk. Arch. 52: 213. 1942. Tipo: Netherlands, Loener, Jansen \& Wachter 41388, Lectotipo: L.

Phalaris canariensis var villosula Jansen \& Wacht., Ned. Kruidk. Arch. 52: 213. 1942. Tipo: Netherlans, Amsterdam, Jansen \& Wachter 29910. Lectotipo: L.

ICONOGRAFÍA. Hitchcock, A.S., Man. Grasses U.S.: 553, fig. 798. 1951.

Nombre vUlgar: alpiste.

Hierbas anuales, de 25-100 cm de alto; entrenudos de 4-18,5 cm de largo, estriados, glabros; nudos glabros. Vainas de 5-12,5 cm de largo, estriadas, glabras; lígulas hialinas, de 4-7,5 cm de largo, truncadas, glabras; láminas de 5-20 cm de largo por (1-)5-10 mm de ancho, glabras. Panículas de 2,5-6 cm de largo por 1-2,5 cm de ancho, espiciformes, ovoides a oblongas, densas, exsertas o parcialmente incluidas en la última vaina foliar. Espiguillas 3-floras, de 5-8 mm de largo; pedicelos de hasta $0,5 \mathrm{~mm}$ de largo, glabros; glumas subiguales, de 5-8 x 1,6-2,3 mm, obovadas a oblanceoladas, glabras, agudas, de color verde pálido con franja longitudinal de color verde más oscuro, la quilla ampliamente alada, alas de 0,6-0,7 mm de ancho, entera. Antecio fértil: lemma de 4,7$5,5 \mathrm{~mm}$ de largo, con pelos adpresos principalmente hacia el ápice; pálea de 4-4,7 mm de largo, ciliada en la quilla hacia el ápice; lodículas de 2,5-3 mm de largo, agudas, glabras. Antecios estériles 2: lemmas bien desarrolladas, 2,5-3,5 x 0,5 $\mathrm{mm}$, alcanzando aproximadamente $1 / 2$ del largo de la lemma fértil, membranosas, subglabras o esparcidamente pilosas.

Número de Cromosomas. 2n = 12 (Hanson \& Hill, 1953).

Distribución GEOGRÁFICA. Especie macaronésicamediterránea (Baldini 1995), cultivada en muchos países del mundo como alimento para aves. En Chile crece entre Copiapó (Región de Atacama) y Osorno (Región de Los Lagos), desde el nivel del mar hasta los $900 \mathrm{~m}$ de altitud.

Material estudiado. CHILE. Región de Antofagasta, Quebrada San Ramón, ca. 6 km NE de Taltal, 50-80 m, 9-XII1987, Dillon \& Teillier 5216 (SGO). Región de Atacama, Prov. Copiapó, Copiapó, en jardín, 350 m, sin fecha, Pisano \& Bravo 935 (SGO). Región de Coquimbo, Los Vilos, 5 m, 3-XI-2006, Tepe et al. 1703 (CONC). Región de Valparaíso, Prov. Valparaíso, Quintero, 35 m, XII-1952, Gunckel
25214 (CONC). Región Metropolitana, Prov. Santiago, Las Vertientes, 850 m, 11-XI-1955, Gunckel 28919 (CONC). Región del Bío-Bío, Prov. Concepción, Concepción, calle Paicaví entre San Martín y Cochrane, 10 m, 4-XII-1988, López 285 (CONC). Región de Los Lagos, Osorno, Fundo Cañal Bajo, Genética de Osorno, sin fecha, García 20 (SGO).

6. Phalaris caroliniana Walter, Fl Carol. 74. 1788. Tipo: USA, South Carolina, McCormick Co., in open field of moist bottomland ca. 1/3 mi due N of Clark Hill Dam, ca. 200 ft., W.H. Duncan 9468 (US).

Phalaris americana Elliott, Sketch Bot. S. Carolina 1: 101, t. 5, f. 4. 1816. Tipo: USA, Carolina, Elliott 25 (Lectotipo: CHARL, no visto).

Phalaris intermedia Bosc ex Poir., Encycl., Suppl. 1: 300. 1810. Tipo: USA, Caroline, Bosc. s.n. (Lectotipo: P).

Phalaris microstachya DC., Cat. Pl. Horti Monsp. 131. 1813. Phalaris intermedia var. microstachya (DC.) Vasey, Contr. U.S. Natl. Herb. 3(1): 42. 1892. P. intermedia var. microstachya (DC.) Vasey ex L.H. Dewey, Contr. U.S. Natl. Herb. 2(3): 512. 1894. Tipo: USA. Americae borealis Carolina australi, Fraser et Bosc. s.n. (Lectotipo: G).

Phalaris occidentalis Nutt., Trans. Amer. Philos. Soc., n.s. 5: 144. 1835. Tipo: Arkansas Territory, Hab. from Fort Smith on the Arkansas to Red River, in partially innundated prairies, flowering in May, T. Nuttall s.n. (Lectotipo: PH).

IcONOGRAFÍA: Hitchcock, A.S., Man. Grasses U.S.: 554, fig. 801. 1951.

Número de CROMosomas: 2n = 28 (Voshell \& Hilu 2014).

Según Voshell \& Hilu (2014) Phalaris caroliniana y $P$. angusta son las únicas especies que se habrían extendido desde el sur de Norteamérica al norte de Sudamérica $\mathrm{y}$, en consecuencia, son los mejores candidatos para un ancestro común con los endemismos sudamericanos como $P$. amethystina. La presencia de $P$. caroliniana en Chile fue descartada por Parodi (1939, 1943), quien bajo $P$. amethystina indica que la referencia de E. Desvaux (1854) a $P$. microstachya se trata en realidad de $P$. amethystina y no de la especie Norteamericana $P$. microstachya $(=P$. caroliniana). También fue descartada por Baldini (1995) quien cita $P$. caroliniana para U.S.A., Puerto Rico y México, introducida en Europa y Australia. No obstante, posteriormente su presencia en Chile fue sostenida por Marticorena \& Quezada (1985) y Zuloaga et al. (2008). Estos últimos autores mencionan para Chile el ejemplar Garaventa 2837, recolectado en la Región de Valparaíso, Quillota, X-1932 (CONC). Esta especie es extremadamente afín a $P$. amethystina desde un punto de vista morfológico, pero genéticamente existen diferencias entre ambas, por lo que no podemos descartar su presencia en el país (ver Voshell et al., 2011, Voshell \& Hilu 2014). 
7. Phalaris coerulescens Desf., Fl. Atlant. 1: 56. 1798. Tipo: Habitat in arvis Algeriae, s.n. (P). Figura 2 A-C.

Phalaris tuberosa Link, J. Bot. (Schrader) 4: 312. 1799[1800], non Ph. tuberosa L. (1771).

Hierbas perennes, de hasta $90 \mathrm{~cm}$ de alto, con engrosamientos bulbosos en la base del tallo. Entrenudos de hasta $14 \mathrm{~cm}$ de largo, estriados, glabros. Vainas de 9-12 cm de largo, más cortas que los entrenudos, estriadas, glabras; lígulas de 10 $\mathrm{mm}$ de largo, hialinas, truncadas, glabras; láminas de 11$24 \mathrm{~cm}$ de largo por 3,5-4 $\mathrm{mm}$ de ancho, planas, estriadas, escabrosas en ambas caras, finamente escabrosas en los márgenes. Panículas de 5-6 cm de largo por 1,5-5,5 cm de ancho, espiciforme, oblonga o elíptica, densa, purpúrea, a veces subincluida en la última vaina foliar. Espiguillas de 6-9 mm, reunidas en grupos de 7, con una espiguilla central fértil sésil o subsésil rodeada de 6 espiguillas pediceladas usualmente masculinas o estériles similares a la espiguilla central. Glumas de 6-9 x 1,3-1,7 mm, lanceoladas, acuminadas, purpúreas hacia el ápice, aladas, alas de 0,05$0,7 \mathrm{~mm}$ de ancho irregularmente dentadas hacia el ápice. Espiguilla fértil central: pedicelo de hasta $1,5 \mathrm{~mm}$; lemma fértil de 3,5 mm de largo, glabra, aguda; lemmas estériles 2 , reducidas a una breve membrana con escasos pelos. Espiguillas masculinas o estériles, pedicelos de 1,5-3 mm de largo, glabros a esparcidamente escabrosos; lemma de 3 $\mathrm{mm}$; pálea de 2,3 mm de largo; estambres de $3 \mathrm{~mm}$ de largo.

Números Cromosómicos. 2n = 14, 28, 42 (Hanson \& Hill 1953, Baldini 1995, Löve \& Kjellqvist 1973).

DistribuCión GEOGRÁfICA. En Norteamérica se encuentra en los Estados Unidos (Soreng et al. 2003). En Sudamérica ha sido citada para Argentina, Brasil y Uruguay (Soreng et al. 2003, Zuloaga et al. 2008). Este es el primer registro de esta especie en Chile. Pasto valioso como forraje (Bews 1918).

Material estudiado. Chile, Región del Bío-Bío, Provincia de Ñuble, Chillán, en las afueras de la ciudad, salida camino a Coihueco, 20-XI-2006, E. Gutiérrez et al. s.n. (CONC-CH). Región de Magallanes y Antártica Chilena, Punta Arenas, Jardín, cultivado, 26-I, 4-II, 1955, O. Magens 3085 (CONC).

8. Phalaris minor Retz., Observ. Bot. 3: 8. 1783. Tipo: Habitat in Oriente. Figura 1 L-M.

Phalaris ambigua Fig. \& De Not., Agrostogr. Aegypt. 10, t. 6. 1851[1853]. Tipo: In arvis humidis Deltae.

Phalaris aquatica var. minor (Retz.) Mutel, Fl. Franc. 4: 15. 1837.

Phalaris arundinacea var. minor (Retz.) Paunero, Anales del Jardín Botánico de Madrid 8: 489. 1948.

Phalaris brevis Trin., Mém. Acad. Imp. Sc. St-Pétersb. Sér. 6, Sci. Math., Seconde Pt, Sci. Nat. 5,3(3): 50. 1839. Lectotipo: Royle s.n. (LE).
Phalaris decumbens Moench, Methodus 208. 1794.

Phalaris gracilis Parl., Pl. Nov. 36. 1842. Phalaris minor var. gracilis (Parl.) Parl., Fl. Ital. 1: 70. 1848. Phalaris minor subsp. gracilis (Parl.) Arcang., Comp. Fl. Ital. 1: 70. 1882. Phalaris minor fo. gracilis (Parl.) Asch. \& Graebn., Syn. Mitteleur. 2(1): 21. 1898. Lectotipo: A. Richard s.n., Ile de Malta (FI).

Hierbas anuales, 30-90 cm de alto; nudos 3-6, glabros; vainas estriadas, glabras, más cortas que los entrenudos; lígula de 5-8 $\mathrm{mm}$ de largo, hialina, truncada, glabra; láminas de 7-25 cm de largo por 5-10 $\mathrm{mm}$ de ancho, planas, glabras. Panícula de (1-) 1,5-5 cm de largo por 1-1,8 cm de ancho, espiciforme, oval, densiflora, de color verde blanquecino. Espiguillas solitarias, homógamas; glumas de 5-5,6 mm de largo, subiguales, agudas, aladas, el ala irregularmente dentada, con nervio medio bien marcado y mancha longitudinal verde en la mitad superior de la quilla; lemma del antecio fértil de 3-3,5 mm de largo por 1,4 mm de ancho, oval, aguda, totalmente pilosa; pálea de $3 \mathrm{~mm}$ de largo; anteras de $2 \mathrm{~mm}$ de largo; antecio estéril 1, lemma de 1-1,1 mm de largo, pilosa.

Número de Cromosomas. 2n = 28 (Keshavarzi et al., 2007). Hanson \& Hill (1953) informan plantas aneuploides con 29 cromosomas.

Distribución geOgrÁfiCA. Especie originaria del Viejo Mundo, se encuentra Eurasia, Norte y Sudamérica, África y Australia. Habita sectores húmedos y sectores cultivados, comportándose como maleza en muchos países (Keshavarzi et al., 2007).

Material estudiado. CHILE, Región de Coquimbo, Prov. de Limarí, Ovalle, Llano del Limarí, 250 m, X-1956, Jiles 3038 (CONC 31345); Ovalle, Infiernillo, González 26-X1986 (SGO 106092); Choapa, cerca de Illapel, X-1958, E. Bailey s.n. (CONC 144656, SGO 132558). Región del BíoBío, Concepción, XII-1925, Barros 679 (CONC 71007); Cosmito, 15 m, 5-XII-1942, Silva \& Jirkal 280 (SGO 148297); Chillán, Jardín de genética de pastos, 114 m, 15X-1941, Jirkal 19 (SGO 148298).

9. Phalaris paradoxa L., Sp. Pl. (ed. 2) 2: 1665. 1763. Tipo: Habitat in Oriente, Forsskal s.n. (LINN 78.6). Figura 2 D-G.

Phalaris praemorsa Lam., Fl. France 3: 56. 1778; P. paradoxa fo. praemorsa (Lam.) Paunero, Anales Jard. Bot. Madrid 8: 486. 1948. P. paradoxa var. praemorsa (Lam.) Coss. \& Durieu, Expl. Sci. Algérie 2: 25. 1855. Tipo: Habitat in oriente et lusitania gallia austr., Forsskal s.n.

Phalaris sibthorpii Griseb., Spic. Fl. Rumel. 2: 468.1844. Tipo: Calabria, Philippi s.n. Lectotipo: GOET. 

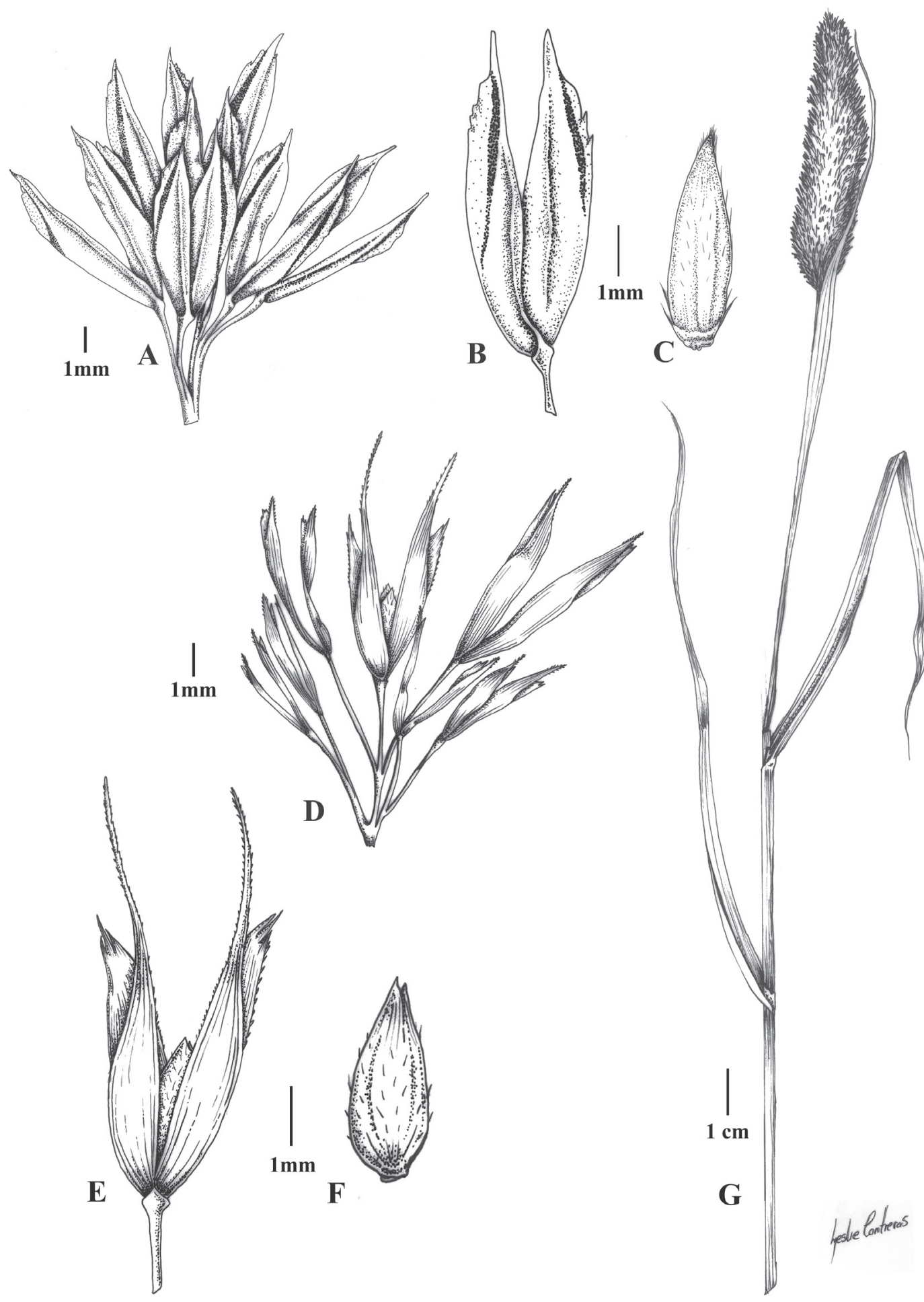

Figura 2. A-C. Phalaris coerulescens Desf. (Gutiérrez et al. s.n.). A. Grupo de espiguillas fértiles y estériles. B. Espiguilla fértil. C. Antecio fértil. D-G. P. paradoxa L. (Finot 2515). D. Grupo de espiguillas fértiles y estériles. E. Espiguilla fértil. F. Antecio fértil. G. Inflorescencia.

Figure 2. A-C. Phalaris coerulescens (Gutiérrez et al. s.n.). A. Cluster of fertile and sterile spikelets. B. Fertile spikelet. C. Fertile floret. D-G. P. paradoxa L. (Finot 2515). D. Cluster of fertile and sterile spikelets. E. Fertile spikelet. F. Fertile floret. G. Inflorescence. 
Phalaris utriculosa L. ex Munro, J. Linn. Soc., Bot. 6: 36. 1862, nomen nudum.

ICONOGRAFÍA. Hitchcock, A.S. 1951: 552, fig. 797; Barkworth 2007: 425.

NomBREs COMUnEs. Hood canary grass, hooded canary grass, bristle-spiked canary grass.

Hierbas anuales, erectas o decumbentes. Cañas de 30-50 $(-100) \mathrm{cm}$ de alto, glabras. Vainas estriadas, glabras, más cortas que los entrenudos, a menudo rojizas; lígula hialina de ca. $5 \mathrm{~mm}$ de largo; láminas planas de 10-15 cm de largo por 3-5(-7) mm de ancho, glabras. Panícula de (2-)3-7 x 2-3 cm, densa, oblonga, verde, teñida de púrpura, enangostándose hacia la base, a menudo incluida en la última vaina foliar. Espiguillas dispuestas en grupos de 7 compuestos de 1 espiguilla central fértil rodeada por 6 espiguillas estériles; espiguilla fértil de 5,5-8 mm; glumas 7-9-nervias, aladas en la quilla, la quilla con un diente triangular prominente en la zona media o tercio superior, el ápice subulado-acuminado a aristado; lemma fértil de $3 \mathrm{~mm}$, mútica; lemmas estériles ausentes o muy reducidas; estambres 3; espiguillas estériles más cortas, con glumas más angostas, éstas con la quilla alado-dentada. Cariopsis de $3 \mathrm{~mm}$ de largo.

Número de Cromosomas. 2n = 14 (Hanson \& Hill, 1953).

Distribución GEOGRÁfiCA. Especie nativa de la región mediterránea, actualmente cosmopolita (Barkworth 2007). En América del Norte se encuentra como maleza en Arizona, California, Washington, etc. (Hitchcock 1951, Barkworth 2007). En América del Sur está presente en Bolivia (Renvoize 1998), Argentina, Uruguay (Zuloaga et al. 2008) y Chile (Finot \& Pedreros 2012). En Chile se encontró como maleza de cultivos de cebolla (Allium cepa L.), coliflor (Brassica oleracea var. botrytis L.) y arveja (Pisum sativum L.) y en canales, sobre suelo arcilloso. Florece en agosto.

Material estudiado. CHILE, Región de O’Higgins, Prov. Colchagua, Santa Cruz, camino Santa Cruz - Lolol km 6 por carretera I-72, 3439'S, 71 ${ }^{\circ} 23^{\prime} \mathrm{W}, 155 \mathrm{~m}, 26-\mathrm{VIII}-2011$, Finot 2515 (CONC, CONC-CH).

\section{AGRADECIMIENTOS}

A Gloria Rojas (SGO) y Alicia Marticorena (CONC) por las facilidades otorgadas para el estudio del material tipo y colecciones generales así como su amable colaboración en el envío de literatura. A Leslie Contreras la confección de ilustraciones. A Paul M. Peterson de Smithsonian Institution su colaboración en la revisión de los tipos de $P$. amethystina y $P$. caroliniana y en la discusión acerca de su identidad. A
Roberto Rodríguez (CONC) y a un revisor anónimo cuyas acertadas sugerencias y comentarios permitieron mejorar este trabajo. Proyecto DIUC 210.121.014-1.0.

Dedico este trabajo a la memoria del Prof. Clodomiro Marticorena P., en recuerdo de sus continuas enseñanzas y constante estímulo.

\section{BIBLIOGRAFÍA}

Anderson, D.H. 1961. Taxonomy and distribution of the genus Phalaris. Iowa State Journal of Science 36: 1-96.

Baeza, C.M., T. Stuessy \& C. Marticorena. 2002. Notes on the Poaceae of Robinson Crusoe (Juan Fernandez) islands, Chile. Brittonia 54: 154-163.

Baeza, C.M., C. Marticorena, T. Stuessy, E. Ruiz. \& M. Negritto. 2007. Poaceae en el archipiélago de Juan Fernández (Robinson Crusoe). Gayana Botánica 64: 25-174.

BALDINI, R.M. 1995. Revision of the genus Phalaris L. (Gramineae). Webbia 49: 265-329.

BALDINI, R.M. \& C.E. JARVIS. 1991. Typification of some Linnaean names in Phalaris (Gramineae). Taxon 40: 475-485.

Barkworth, M.E. 2007. Phalaris L. In: M.E. Barkworth, L.K. Anderton, K.M. Capels, S. Long \& M.B. Piep (eds.), Manual of grasses for North America. Pp. 177-179, 425426, 529-530. Utah State University Press, Utah, 626 pp.

Bews, J.M. 1918. The grasses and grassland of South Africa. P. Davis \& Sons, Ltd., Pietermaritzburg. 161 pp.

Clayton, W.D. \& S.A. Renvoize. 1986. Genera graminum. Grasses of the world. Kew Bulletin Additional Series XIII, London, $389 \mathrm{pp}$.

Colegate, S.M., N. Anderton, J. Edgar, C.A. Bourke \& R.N. ORAM. 1999. Suspected blue canary grass (Phalaris coerulescens) poisoning to horses. Australian Veterinary Journal 77: 537-538.

Desvaux, E. 1854. Gramíneas. En: C. Gay, Historia Física y Política de Chile, Botánica 6: 233-469.

Finot, V.L. \& J.A. Pedreros. 2012. Phalaris paradoxa L. (Poaceae: Phalaridinae), a new introduced weed species in Central Chile. Gayana Botánica 69(1): 110-113.

Hanson, A.A. \& H.D. HiLl. 1953. The occurrence of aneuploidy in Phalaris spp. Bulletin of the Torrey Botanical Club 80: $16-20$.

Hitchсоск, A.S. 1951. Manual of the grasses of the United States $\left(2^{\text {nd }}\right.$ ed). U.S.D.A. Burreau of Plant Industry, Miscellaneous. Publication $\mathrm{N}^{\circ}$ 200. Washington, DC. $1051 \mathrm{pp}$.

Hodson, M.J., A.G. Sangster \& D.W. Parry. 1984. An ultrastructural study on the development of silicified tissues in the lemma of Phalaris canariensis L. Proceedings of the Royal Society of London, Series B, Biological Sciences 222: 413-425.

Holmgren, P.K., N.H. Holmgren \& L.C. Barnett. 1990. Index herbariorum. Part I. The herbaria of the world, ed. 8. Regnum Vegetabile 120: 1-693.

Keshavarzi, M., M. Khaksar \& M. Seifali. 2007. Systematic study of annual weed Phalaris minor Retz (Poaceae) in Iran. Pakistan Journal of Biological Sciences 10: 1336-1342.

Löve, A. \& E. KJellqvist. 1973. Cytotaxonomy of Spanish plants. 
Lagascalia 3(2): 147-182.

Marticorena, C. \& M. Quezada. 1985. Catálogo de la flora vascular de Chile. Gayana Botánica 42: 1-147.

NicorA, E.G. 1978. Gramineae. En: M.N. Correa (ed.), Flora Patagónica. Colecciones Científicas INTA, Buenos Aires, Argentina, 563 pp.

Nicora, E.G. \& Z. Rúgolo. 1987. Los géneros de Gramíneas de América Austral, Argentina, Chile, Uruguay, y áreas limítrofes de Bolivia, Paraguay y Brasil. Ediciones Hemisferio Sur S.A., Buenos Aires, 611 pp.

Nielsen, E.L. \& L.M. Humphrey. 1937. Grass studies. I. Chromosome numbers in certain members of the tribes Festuceae, Hordeae, Aveneae, Agrostideae, Chlorideae, Phalarideae and Tripsaceae. American Journal of Botany 24: 276-279.

Offord, M. 2006. Plants poisonous to horses. An Australian field guide. RIRDC Publ. N06/048, 121 pp.

PArodi, L.R. 1939. El género Phalaris en Chile. Revista Argentina de Agronomía 6: 77-84.

PArodi, L.R. 1943. Las especies del género Phalaris de la flora chilena. Revista Chilena de Historia Natural 45: 130136.

Paunero, E. 1948. Revisión de las especies españolas del género Phalaris. Anales del Jardín Botánico de Madrid 8: 475522.

Perry, C.C., S. Mann \& R.J.P. Williams. 1984. Structural and analytical studies of the silicified macrohairs from the lemma of the grass Phalaris canariensis L. Proceedings of the Royal Society of London, Series B, Biological Sciences 222: 427-438.

PhILIPPI, R.A. 1864. Plantarum novarum Chilensium. Linnaea 33: 1-308.

Quintanar, A., S. Castroviejo \& P. Catalán. 2007. Phylogeny of the tribe Aveneae (Pooideae, Poaceae) inferred from plastid trnT-F and nuclear ITS sequences. American Journal of Botany 94: 1554-1569.

Renvoize, S.A. 1998. Gramíneas de Bolivia. The Royal Botanical Garden, Kew. 644 pp.

Rúgolo, Z.E., E. Nicora, A.M. Molina, J. Mujica-Sallés \& A. ZANIN. 2008. Gramineae VII. In: L. Ramella \& P. Perret (eds.), Flora del Paraguay - 38. Ed. Conservatoire et Jardin botaniques de la Ville de Genève, 98 pp.

Rúgolo, Z.E., P.E. Steibel \& H.O. Troiani. 2005. Manual ilustrado de las gramíneas de la provincia de La Pampa. Editorial Universidad Nacional de La Pampa y Editorial Universidad de Río Cuarto, Argentina, 374 pp.

Safrela, J.M., Qing Liu, P.M. Peterson, R.J. Soreng \& B. Paszko.
2010. Phylogenetics of the grass 'Aveneae-Type Plastid DNA Clade' (Poaceae: Pooideae, Poeae) based on plastid and nuclear ribosomal DNA sequence data. In: O. Seberg, Petersen, Barfod \& Davis (eds.), Diversity, Phylogeny and Evolution in the Monocotyledons. Pp. 557-586, Aarhus University Press, Copenhagen, Denmark.

SAInT-LÉGER, L. 1889. Étude des Fleurs, ed. 8 2: 900.

Soreng, R.J., P.M. Peterson, G. Davidse, E.J. Judziewicz, F.O. Zuloaga, T.S. Filgueiras \& O. Morrone (eds.). 2003. Catalogue of New World grasses (Poaceae): IV. subfamily Pooideae. Contributions from the United States National Herbarium 48: 1-730.

SousA, R.S. \& L.F. IRIGOYEN. 1999. Intoxicação experimental por Phalaris angusta (Gramineae) en bovinos. Pesquisa Veterinaria Brasileira 19: 116-122.

Steudel, E.G. 1853 [1855]. Synopsis plantarum glumacearum. Stuttgart 2 vols.- pars I. Gramineae. Synopsis plantarum graminearum. ii-vii, $474 \mathrm{pp}$.

Steudel, E.G. 1857. Berberides Americae Australis 56. 1857.

Tovar, O. 1993. Las gramíneas (Poaceae) del Perú. Ruizia 13: $1-480$.

Trinius, C.B. 1839. Mémoires de l'Académie Impériale des Sciences de Saint-Pétersbourg. Sixième Série. Sciences Mathématiques, Physiques et Naturelles. Seconde Partie: Sciences Naturelles 5,3(3): 56. 1839.

Tucker, G.C. 1996. The genera of Pooideae (Gramineae) in the Southeastern United States. Harvard Papers in Botany 9: 11-90.

Tzvelev, N. 1983. Grasses of the Soviet Union [Zlaki SSSR]. Botanicheskii Institu im. V.L. Komarova and Smithsonian Institution, Amerind Publ., New Delhi.1196 pp.

Tzvelev, N.N. 1989. The system of grasses (Poaceae) and their evolution. The Botanical Review 55: 141-203.

Voshell, S.M., R.M. Baldini, R. Kumar, N. Tatalovich \& K.W. HiLu. 2011. Canary grass (Phalaris, Poaceae): molecular phylogenetics, polyploidy and floret evolution. Taxon 60: 1306-1316.

Voshell, S.M. \& K.W. Hilu. 2014. Canary grass (Phalaris, Poaceae): biogeography, molecular dating and the role of the floret structure in dispersal. Molecular Ecology 23: 212-224.

Zuloaga, F.O., O. Morrone \& M. Belgrano. 2008. Catálogo de las plantas vasculares del Cono Sur. Vol. 1: Pteridophyta, Gymnospermae, Monocotyledoneae. Monographs in Systematic Botany 107, Missouri Botanical Garden Press, St. Louis, Missouri, USA.

Recibido: 28.11 .12

Aceptado: 17.04 .14 